\title{
Correction to: Beyond big versus small: assessing spatial variation of urban neighborhood block structures in high-density cities
}

\author{
ChengHe Guan ${ }^{1,2,3}$ (D) Peter G. Rowe ${ }^{4}$
}

Published online: 17 March 2021

(c) Springer Nature Singapore Pte Ltd. 2021

\section{Correction to: Socio-Ecological Practice Research https://doi.org/10.1007/s42532-021-00074-7}

Due to an unfortunate oversight during the correction process, some mistakes occurred. We offer our mea culpa to the said authors and provide the following corrections.

The copyright line should read: () Springer Nature Singapore Pte Ltd. 2021;

The references in Sect. 2.2.2. (on fourth line in the first paragraph) should be (Song et al. 2013; Guan and Rowe, 2016);
In the reference section the reference "Guan C, Rowe, $\mathrm{P}$ (2016) The concept of urban intensity and China's townization policy: Cases from Zhejiang Province. Cities, 55, 22-41. https://doi.org/10.1016/j.cities.2016.03.012" should be added;

Also in the reference section, Xiang W-N (2019) Ecopracticology: the study of socio-ecological practice. Socio Ecol Pract Res 1:7-14 is the correct reference.

The original article has been corrected.

The original article can be found online at https://doi.org/10.1007/ s42532-021-00074-7.

ChengHe Guan

Arts and Sciences, New York University Shanghai, Shanghai, China

2 Shanghai Key Lab for Urban Ecological Processes and Eco-Restoration, East China Normal University, Shanghai, China

3 PEAK Urban Programme, University of Oxford, Oxford, UK

4 Department of Urban Planning and Design, Graduate School of Design, Harvard University, Cambridge, USA 